\title{
Power Converter Topologies with Energy Recovery and Grid Power Limitation For Inductive Load Applications
}

\author{
Stefano Rossini, Konstantinos Papastergiou, Gilles Le Godec \\ CERN, Geneva, Switzerland, \\ Sebastián Maestri, Rogelio Garcia Retegui, \\ UNIVERSIDAD NACIONAL DE MAR DEL PLATA L.I.C, Mar del Plata, Argentina
}

Keywords: converter control, power management, physics research, power supply, accelerators

\begin{abstract}
This work investigates a grid interface for power supplies used in particle accelerators for cycling loads such as large electromagnets. Two topologies are discussed integrating magnetic energy recovery. For each topology, the associated energy management strategies are examined with the objective to control the grid current profile. A model is established for each of the proposed solutions and the simulation results are presented. A critical review of the investigated energy management solutions is attempted.
\end{abstract}

Presented at: EPE 2015, 7-10 September 2015, Geneva, Switzerland

Geneva, Switzerland

October, 2015 


\title{
Power Converter Topologies with Energy Recovery and Grid Power Limitation
}

\section{For Inductive Load Applications}

\author{
Stefano Rossini ${ }^{1}$, Konstantinos Papastergiou ${ }^{1}$, Gilles Le Godec ${ }^{1}$, Rogelio Garcia Retegui ${ }^{2}$ and Sebastian Maestri ${ }^{2}$ \\ ${ }^{1}$ European Organisation for Particle Physics - CERN \\ Technology Department \\ 1211 Geneva, Switzerland \\ ${ }^{2}$ Universidad Nacional de Mar Del Plata - L.I.C. \\ Juan B.Justo 4302 \\ Mar del Plata, Argentina
}

\begin{abstract}
This work investigates a grid interface for power supplies used in particle accelerators for cycling loads such as large electromagnets. Two topologies are discussed integrating magnetic energy recovery. For each topology, the associated energy management strategies are examined with the objective to control the grid current profile. A model is established for each of the proposed solutions and the simulation results are presented. A critical review of the investigated energy management solutions is attempted.
\end{abstract}

$\underline{\text { Keywords: }}$ converter control, power management, physics research, power supply, accelerators

\section{INTRODUCTION}

Many electromagnets (often simply referred to as "magnets") currently used in a particle physics accelerators date back several decades. At the time, switch mode power converters were not widely deployed [1]. Even nowadays many magnets in experimental zones still operate in continuous (DC) current and are powered by thyristor converters used in single quadrant operation. For magnets used in particle transfer lines - delivering particles from an accelerator to another or directly to physics experiments - the magnetic energy is cycled (electrical current is cycled between two or more values) between Physics operations. A two-quadrant thyristor bridge can return energy back to the grid while de-energising the magnet simply by adjusting its firing angle $\left(90^{\circ}<\alpha<180^{\circ}\right)$. Thyristor converters however consume reactive power [3] [4] and degrade the power quality in the grid [5]. Hence a reactive power compensation system based on SVCs [6] [7] [8] has to be implemented.

A key objective in new generation of Physics Accelerators is the efficient use of electrical energy. In order to reduce energy consumption, continuous powering of the magnets is to be avoided. A cycling current operation is instead preferred where this is possible where beam is present in the magnets for short periods of time (typically less than $10 \mu$ s over a period of $1 \mathrm{~s})$.

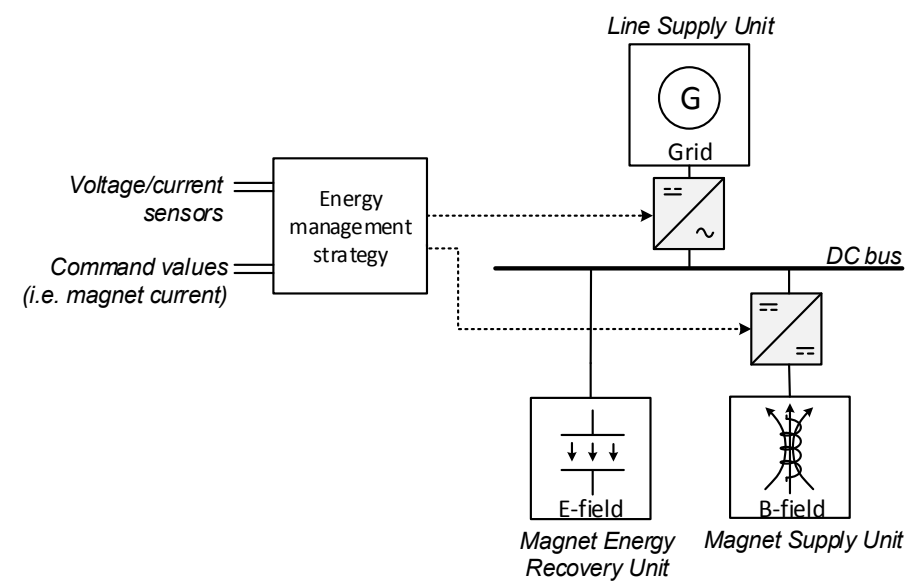

This paper presents two solutions to the problem of energy (and power) management based on classical switch mode power supplies topologies. One solution consists of a Boost converter connected after a 3-phase diode rectifier and its associated DC-link inductor. The schematics is similar to the Boost PFC application used in single-phase applications [9] [10]. In this application the Boost stage is used in order to regulate the grid current rather than increasing the power factor (which is already good enough - for a 3-phase diode bridge rectifier PF $=0.955$ ). This could also be achieved by using an Active Front End (AFE) grid interface, although since returning energy back to the grid is not required its benefits are limited compared to the additional complexity in control and measurement devices.

Another solution which is investigated consists of a 2Q converter (bidirectional current converter, Half-Bridge) placed in parallel to the DC-link capacitor.

\section{THE APPLICATION}

A load cycle comprises of a current increment to the required value, a flat-top of a certain duration during which a Physics operation takes place (e.g. a beam extraction from the accelerator), followed by a current decrease to a minimum 
value (or zero) where it remains to save power. During the current decrease interval the energy stored into the magnetic field is being recovered in capacitors banks.

In this study a $1.2 \mathrm{sec}$ cycling period has been selected. A number of such cycles have been assembled into a super-cycle illustrated in Figure 1, representing a typical pattern of the transfer line magnet current. The load characteristics, required current magnitude, the power converter DC-link voltage variation, peak RMS power ratings as well as the nominal grid conditions are all summarised in Table 2.

TABLE 1

APPLICATION SPECIFICATIONS

\begin{tabular}{ccc}
\hline System & Parameter & Value \\
\hline & $L_{\text {magnet }}$ & $0.13 \mathrm{H}$ \\
& $R_{\text {magnet }}$ & $0.2 \Omega$ \\
Magnet characteristics & $I_{\max }$ & $900 \mathrm{~A}$ \\
& $U_{\max }$ & $450 \mathrm{~V}$ \\
& $d I_{\text {magnet }} / d t$ & $2000 \mathrm{~A} / \mathrm{s}$ \\
\hline \multirow{2}{*}{ Converter DC-link } & $U_{D C, \min }$ & $600 \mathrm{~V}$ \\
& $U_{D C, \max }$ & $1000 \mathrm{~V}$ \\
\hline \multirow{2}{*}{ Grid interface rating } & $U_{N}$ & $400 \mathrm{~V}$ \\
& $I_{N}$ & $125 \mathrm{~A}$ \\
\hline
\end{tabular}

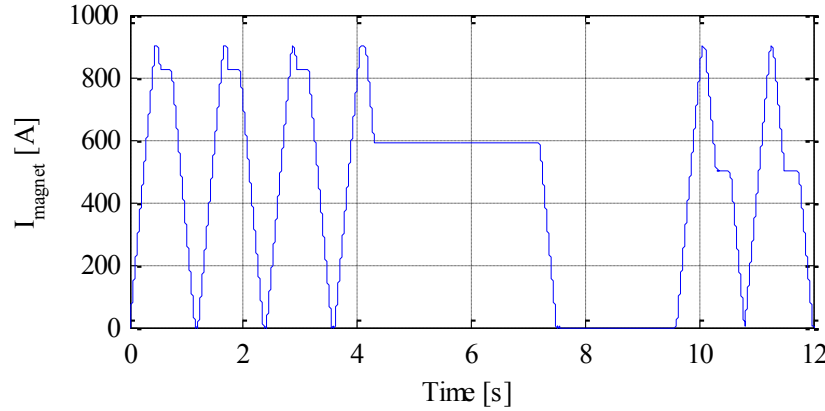

Figure 1: Load super-cycle

Cycling of the magnets results in lower RMS power losses in comparison with the RMS power losses in continuous load current. The RMS current rating of power converters (including the power network interface equipment such as medium to low voltage transformers, cabling and switchgear) can thereby be rated for lower current with consequent cost savings. To reduce the grid interconnection costs by using standard three phase low voltage $(400 \mathrm{~V})$ circuit breakers the power converter input peak current shall be capped to no more than 1.5 times the rated RMS current under nominal grid conditions.

Furthermore, undisturbed operation of the power converter is desired during short grid faults such as a 50ms disconnection event (upstream of the power converter) due to a lightning strike for example. To demonstrate the effectiveness of each topology and control strategy against normal and disturbed grid conditions the following cases have been examined in this work:

- A stable grid voltage fixed at nominal voltage $U_{\mathrm{N}}$ across all three phases

- A short $(100 \mathrm{~ms})$ over-voltage event of $\mathrm{U}_{\mathrm{N}}+10 \%$ across all three phases

- A short (50ms) grid disconnection fault (upstream of the converter) with $0 \mathrm{~V}$ across all three phases

\section{CONVERTER TOPOLOGIES}

Two converter topologies have been investigated with the objective of controlling the converter input power. A series connected boost regulator can act as a power flow controller by regulating the DC-link current (Figure 2a). The DC-link capacitors are effectively the energy storing component. Alternatively, a two-quadrant DC-DC regulator is connected in parallel to the DC-link and a dedicated energy storing capacitors are connected on its low voltage side (Figure 2b).

The magnet power supply consists of one H-bridge module together with an output filter. For the purpose of this study the switching behaviour of the magnet supply unit can be neglected. The H-bridge magnet supply and the magnet load can therefore be modelled as a controlled current source (see Figure 2) drawing the specified magnet power from the DC-link. The current that flows into the load-equivalent source is given by:

$$
i_{e}(t)=\frac{p_{\text {magnet }(t)}}{u_{D C}(t)}=\frac{i_{\text {magnet }}(t) \cdot u_{\text {magnet }}(t)}{u_{D C}(t)}
$$




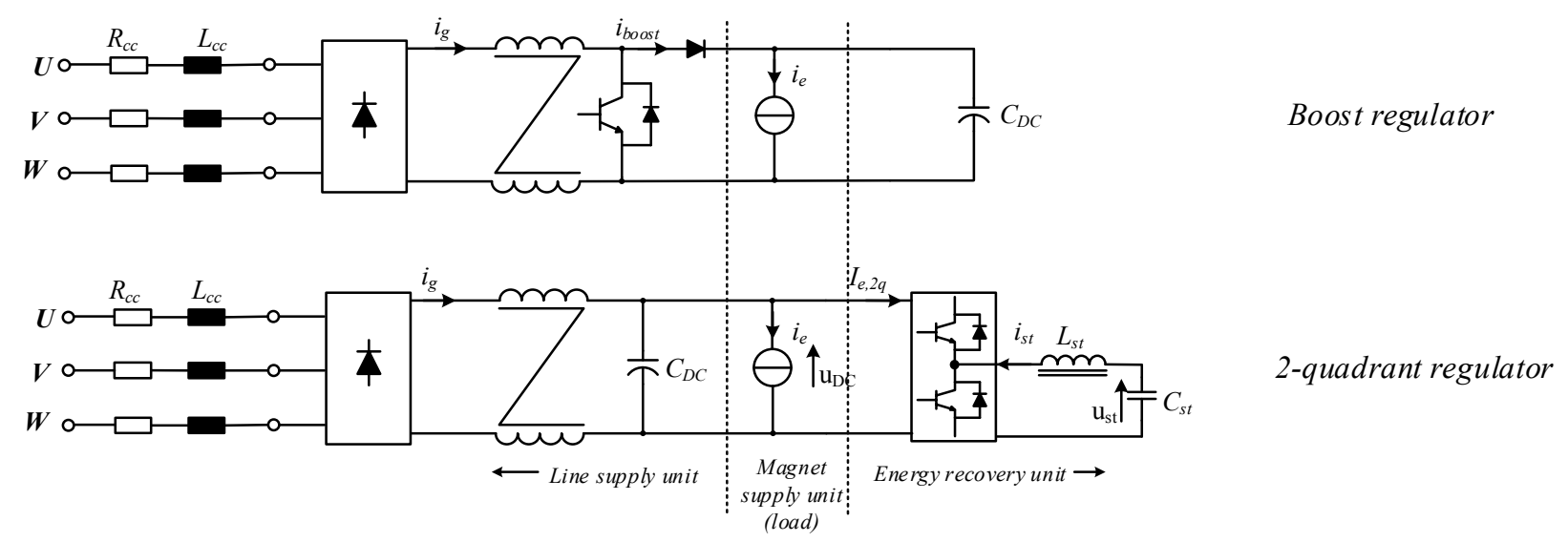

Figure 2: Simplified converter topology diagrams. A boost DC-DC regulator is used to control the current flow into the DC-link (upper) and a 2-quadrant energy storing converter is used to regulate the DC-link voltage (lower).

In TABLE 2 the values of the components used in the different topologies have been outlined.

\begin{tabular}{cccc}
\multicolumn{4}{c}{ TABLE 2: SIZING OF COMPONENTS } \\
\hline Parameter & Boost & 2Q (Power Balance) & 2Q (Rule Based Control) \\
\hline $\mathbf{S}_{\mathbf{N}}$ & $86.6 \mathrm{kVA}$ & $86.6 \mathrm{kVA}$ & $86.6 \mathrm{kVA}$ \\
$\mathbf{U}_{\mathbf{2 0 , \mathbf { N }}}$ & $300 \mathrm{~V}$ & $600 \mathrm{~V}$ & $600 \mathrm{~V}$ \\
$\mathbf{I}_{\mathbf{2 0 , \mathbf { N }}}$ & $166.7 \mathrm{~A}$ & $83.3 \mathrm{~A}$ & $83.3 \mathrm{~A}$ \\
$\mathbf{L}_{\mathbf{c c}}$ & $0.198 \mathrm{mH}$ & $0.793 \mathrm{mH}$ & $0.793 \mathrm{mH}$ \\
$\mathbf{R}_{\mathbf{c c}}$ & $0.0156 \mathrm{~m} \Omega$ & $0.0623 \mathrm{~m} \Omega$ & $0.0623 \mathrm{~m} \Omega$ \\
$\mathbf{L}_{\mathbf{D C}}$ & $1 \mathrm{mH}$ & $1 \mathrm{mH}$ & $4 \mathrm{mH}$ \\
$\mathbf{C}_{\mathbf{D C}}$ & $350 \mathrm{mF}$ & $10 \mathrm{mF}$ & $10 \mathrm{mF}$ \\
$\mathbf{L}_{\mathbf{s t}}$ & - & $0.250 \mathrm{mH}$ & $0.250 \mathrm{mH}$ \\
$\mathbf{C}_{\mathbf{s t}}$ & - & $700 \mathrm{mF}$ & $700 \mathrm{mF}$ \\
\hline
\end{tabular}

\section{CONTROL STRUCTURE / ARCHITECTURE}

\section{A. Boost converter}

The boost series-connected stage acts as a power flow controller from the power Grid to the voltage source converter magnet supply. The power flow control is based on a strategy block that is described in section V of this paper. The DClink voltage control is performed by the control block illustrated in Figure 3 . The reference voltage is provided by the control strategy block and is then compared with actual voltage measurement. A PI controller is used to create the required response while the grid current limitation is implemented after this stage using an anti-windup implementation. The boost current controller finally sets the duty cycle of the boost IGBT according to the defined limits.

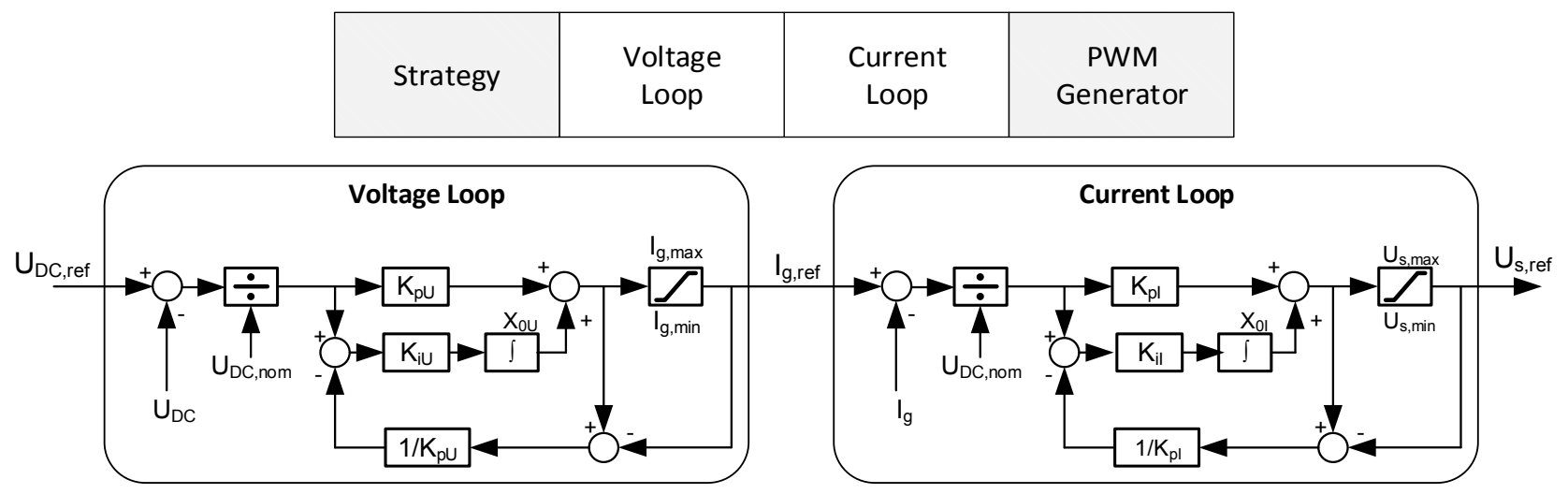

Figure 3: the voltage and current controllers used for the boost stage

\section{B. $2 Q$ converter}

The 2-quadrant parallel-connected stage acts as an energy buffer by providing and absorbing the reactive power of the magnet. The power flow control is based on a strategy block that is described in section $\mathrm{V}$ of this paper. The 2-quadrant 
solution requires a current loop with feed-forward of the voltage across the storage capacitors in order to control the current into the storage capacitor $\left(\mathrm{I}_{\mathrm{st}}\right)$. After this a DC-link voltage compensation loop is implemented to account for the fast variations of the DC-link voltage.

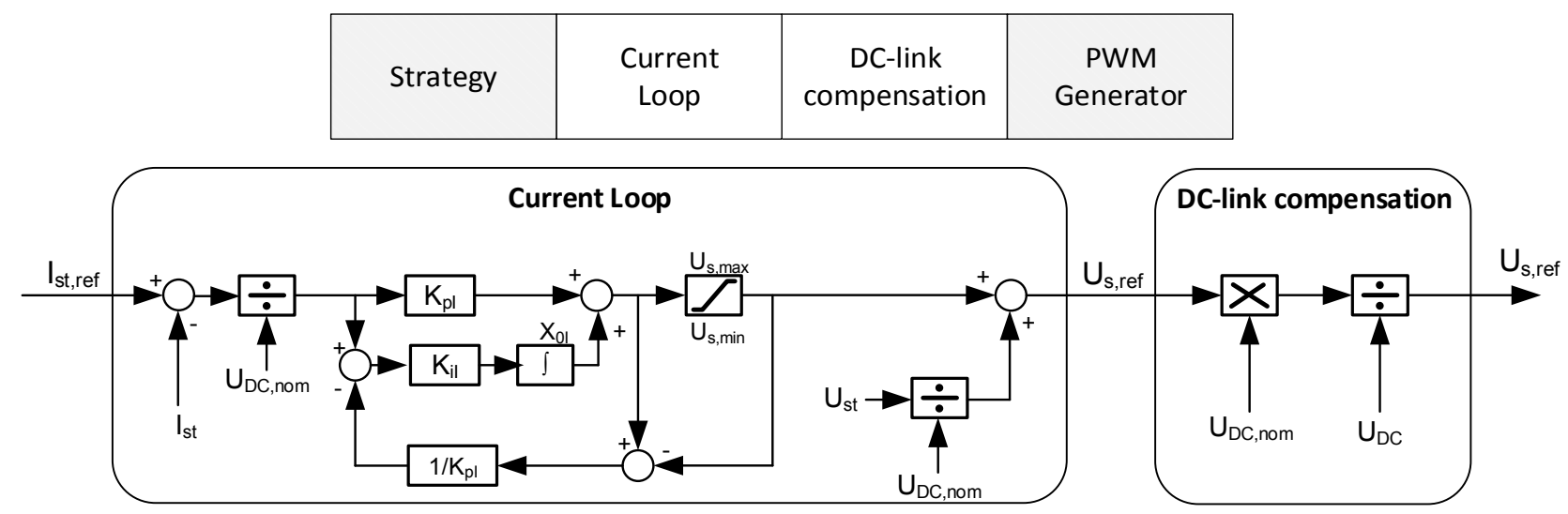

Figure 4: the current controller and DC-link compensation loops used for the 2-quadrant stage

The control coefficients used in the simulation models have been summarised in TABLE 3 .

\begin{tabular}{cc} 
& \\
\hline Parameter & Boost \\
\hline $\mathrm{U}_{\mathrm{DC}, \text { nom }}$ & $900 \mathrm{~V}$ \\
$\mathrm{U}_{\mathrm{DC}, \mathrm{ref}}$ & $600 \mathrm{~V} \ldots 900 \mathrm{~V}$ \\
$\mathrm{~K}_{\mathrm{pU}}$ & 20000 \\
$\mathrm{~K}_{\mathrm{iU}}$ & 5000 \\
$\mathrm{X}_{0 \mathrm{U}}$ & $0 \mathrm{~A}$ \\
$\mathrm{I}_{\mathrm{g}, \max }$ & $215 \mathrm{~A}$ \\
$\mathrm{I}_{\mathrm{g}, \min }$ & $0 \mathrm{~A}$ \\
$\mathrm{~K}_{\mathrm{pI}}$ & 50 \\
$\mathrm{~K}_{\mathrm{iI}}$ & 100 \\
$\mathrm{X}_{0 \mathrm{I}}$ & 0 \\
$\mathrm{U}_{\mathrm{s}, \max }$ & +1 \\
$\mathrm{U}_{\mathrm{s}, \min }$ & -1 \\
\hline
\end{tabular}

TABLE 3: CONTROLLER COEFFICIENTS

\begin{tabular}{ccc}
\hline Parameter & 2Q (Power Balance) & 2Q (Rule Based Control) \\
\hline $\mathrm{U}_{\mathrm{DC}, \text { nom }}$ & $810 \mathrm{~V}$ & $810 \mathrm{~V}$ \\
$\mathrm{I}_{\mathrm{st}, \mathrm{ref}}$ & $-1500 \mathrm{~A} \ldots+1500 \mathrm{~A}$ & $-3000 \mathrm{~A} \ldots+3000 \mathrm{~A}$ \\
$\mathrm{~K}_{\mathrm{pI}}$ & 2 & 2 \\
$\mathrm{~K}_{\mathrm{iI}}$ & 25 & 50 \\
$\mathrm{X}_{0 \mathrm{I}}$ & 0 & 0 \\
$\mathrm{U}_{\mathrm{s}, \max }$ & +1 & +1 \\
$\mathrm{U}_{\mathrm{s}, \min }$ & -1 & -1 \\
\hline
\end{tabular}

\section{CONTROL STRATEGY}

\section{A. Boost converter: Energy Balance Strategy}

This strategy assumes that the total energy stored across all storage elements (magnet \& DC-link capacitors) is constant. The average (resistive) power losses are not included in the energy balance and will consequently be supplied by the AC grid connection. Assuming $\mathrm{u}_{\mathrm{DC}, \max }$ as the maximum voltage on the DC-link capacitor:

$$
e_{\text {stored }}(t)=e_{D C, \text { capacitor }}(t)+e_{\text {magnet }}(t)=\frac{1}{2} \cdot C_{D C} \cdot u_{D C}^{2}(t)+\frac{1}{2} \cdot L_{\text {magnet }} \cdot i_{\text {magnet }}^{2}(t)=\frac{1}{2} \cdot C_{D C} \cdot u_{D C, \text { max }}^{2}
$$

And hence the DC-link voltage reference fed to the DC-link voltage controller is therefore:

$$
u_{D C, \text { ref }}(t)=\sqrt{V_{D C, \text { max }}^{2}-\frac{L_{\text {magnet }}}{C_{D C}} \cdot i_{\text {magnet }}^{2}(t)}
$$

The grid power is bounded by limiting the current in the boost inductor. When working in current limitation mode, active power will (at least partly) be provided by the DC-link capacitor, which will cause an error between the reference voltage and the measured voltage.

\section{B. $2 Q$ converter: Power Balance Strategy}

In this strategy the power conservation law is considered (power delivered by DC-link capacitor is neglected as it will be zero on average). The required inputs to this strategy are the voltage and current of the energy storing capacitor of the 2 - 
quadrant converter, the DC-link voltage and the magnet power. The power given or absorbed by the 2-quadrant energy storing converter is:

$$
P_{2 Q}=P_{\text {magnet }}-P_{\text {grid }}
$$

The 2-quadrant converter capacitor recharge current is proportional to its depth of discharge and hence the power can be written as:

$$
P_{2 Q}=I_{e} \cdot U_{D C}-U_{s t} \cdot k_{\text {recharge }} \cdot\left(U_{s t, \max }-U_{s t}\right)
$$

where the second term, proportional to the voltage of the storage element, is limited by the load requirements or the AC grid connection ratings (whichever is lower).

The control scheme for this strategy provides a current reference $\mathrm{I}_{\mathrm{st}, \text { ref }}$ to the 2-quadrant converter current controller which is given in Figure 4. The associated control strategy is illustrated in Figure 5(a). The control coefficients are reported in TABLE 4.

\section{C. $2 Q$ converter: Rule Based Control Strategy}

The Power Balance Strategy presented in the previous paragraph is conceptually simple and implementation can be made with minimum voltage and current sensing. This however has been found to impair the circuit's ability to handle grid disturbances. In case of a grid overvoltage, for example, uncontrolled current flows into the DC-link and hence the grid current limitation is lost. The rule based control introduces an observer that evaluates the DC-link voltage and grid current before applying the governing control equation. When the grid is in a normal state, the Power Balance Strategy is applied. When overvoltage is detected on the DC-link a control loop takes over to rectify this quickly before an overcurrent occurs on the grid side. If an undervoltage occurs on the DC-link, a control look enforces a minimum voltage value in order to ensure the continuity of operation of the magnet supply. A last rule checks the rectified grid current and in case the grid current limit is exceeded a fast current limiting action is taken, by raising as fast as possible the DC-link voltage. The control strategy is illustrated in Figure 5b while the control coefficients are reported in TABLE 4.

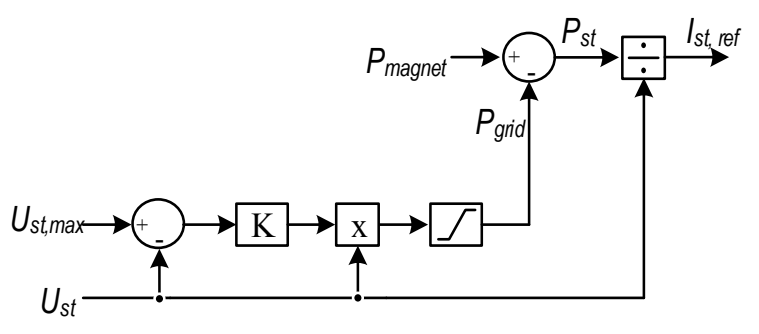

(a)

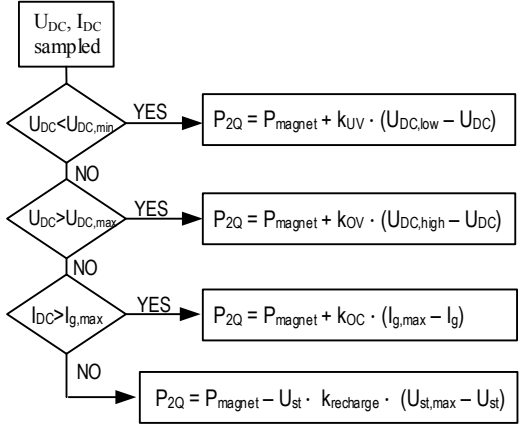

(b)

Figure 5: (a) Power Balance and (b) Rule Based Control strategy

\begin{tabular}{ccc} 
TABLE 4: 2-QUADRANT CONTROL STRATEGIES COEFFICIENTS \\
\hline Parameter & 2Q (Power Balance) & 2Q (Rule Based Control) \\
\hline Ust,max $_{\text {St, }}$ & $600 \mathrm{~V}$ & $600 \mathrm{~V}$ \\
$\mathrm{~K}_{\text {recharge }}$ & 5 & 5 \\
UDC,low & - & $700 \mathrm{~V}$ \\
$\mathrm{U}_{\mathrm{DC}, \text { high }}$ & - & $950 \mathrm{~V}$ \\
$\mathrm{I}_{\mathrm{g}, \max }$ & - & $130 \mathrm{~A}$ \\
$\mathrm{~K}_{\mathrm{UV}}$ & - & 500 \\
$\mathrm{~K}_{\mathrm{OV}}$ & - & 5000 \\
$\mathrm{~K}_{\mathrm{OC}}$ & - & 6000 \\
\hline
\end{tabular}

\section{SIMULATION RESULTS}

\section{A. Nominal grid Conditions}

A simulation is performed with the current reference of Figure 1 being applied to the magnet supply to evaluate the system behaviour during a typical load super-cycle. The results of Figure 6 illustrate the grid current waveforms (top) and the energy storing capacitor voltage waveforms (bottom) for the three considered solutions, simulated under nominal grid 
conditions. The grid current values (Figure 6 top figures) are normalised to the equivalent rectified DC current of a $400 \mathrm{~V} / 125 \mathrm{~A}$ grid interface in order to make them comparable for the different topologies.

The boost converter results presented in Figure 6(a) prove the effectiveness of the grid current limitation to $1.15 \mathrm{pu}$ with a high frequency ripple component in it. The boost being a series connected stage allows a fast dynamic response to DC-link variations and hence the DC-link voltage follows quite accurately the load variations and a $350 \mathrm{~V}$ fluctuation is seen.

The 2-quadrant converter grid current and DC-link voltage waveforms are illustrated in Figure 6(b) and Figure 6(c). A higher peak grid current $(1.25 \mathrm{pu})$ is exhibited while the DC-link voltage is kept relatively stable since the grid power is almost constant and the varying power flow originates from the 2-quadrant storage capacitor (voltage fluctuation of $350 \mathrm{~V}$ ). It can be noticed that the rule based control (Figure 6(c)) performs better with regards to the input current ripple but this is a result of a higher input reactance that was required with this strategy in order to allow more time for the controllers to respond to grid events. The three proposed topologies satisfy the grid constraints. After one cycle the storage element (either the DC-link capacitor or the additional storage element capacitor) is fully recharged.
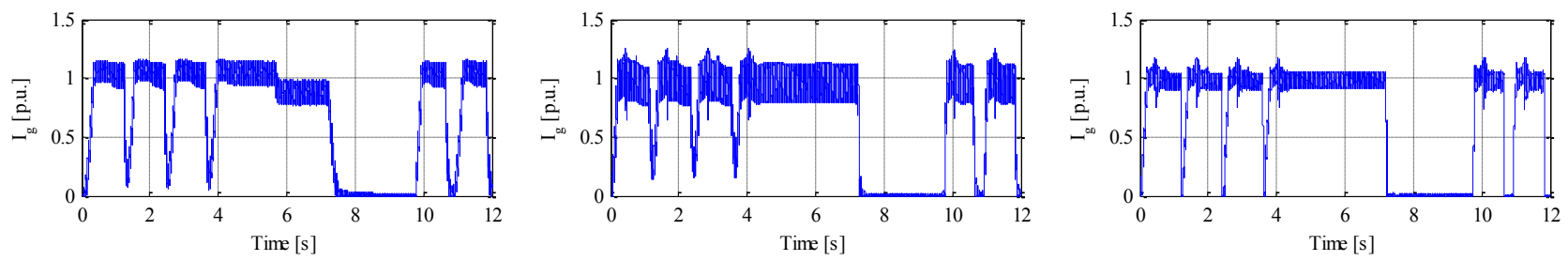

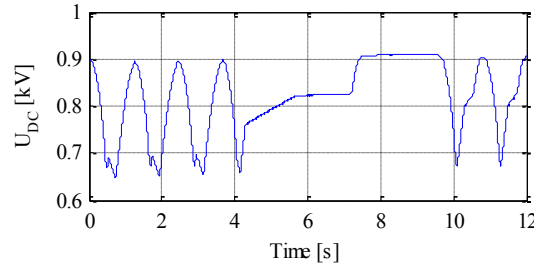

(a)

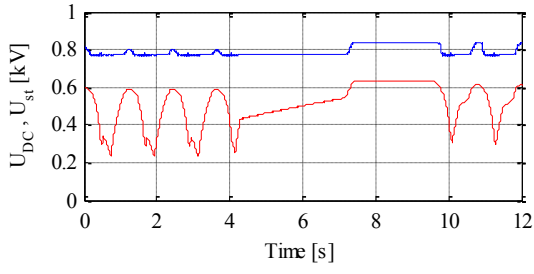

(b)

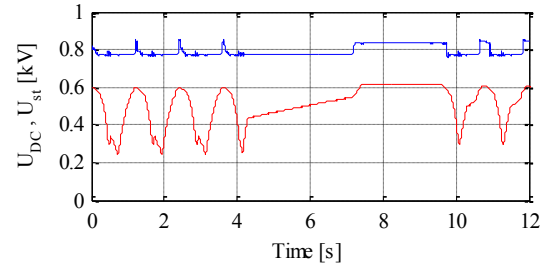

(c)

Figure 6: Grid current waveforms (top) and energy storing capacitor voltage (bottom). (a) Boost converter (b) twoquadrant converter with power balance control strategy and (c) two-quadrant converter with rule-based control strategy.

\section{B. Grid overvoltage transients}

Figure 7 presents the simulation results of the discussed topologies during grid over-voltage event (10\% overvoltage during $100 \mathrm{~ms}$ ). Figure 7(a) shows that the Boost converter rejects grid perturbations with a virtually constant peak current of 1.16 p.u.. On the other side, Figure 7(b) demonstrates a disturbance event on the 2Q converter input current waveform and consequently on the storage element voltage (focusing on the first magnet current pulse between 0 and 1.2 seconds). It is seen that the Power Balance Control strategy is not able to limit the overcurrent caused by the over-voltage, This is due to the uncontrolled diode rectifier diodes that allow an equally uncontrolled current to flow towards the DC-link.

To restrict an AC current surge the 2-quadrant converter must respond fast to increase the DC-link voltage in order to reduce the conduction time of the diode rectifier. This can be done more effectively with a rule based control as seen in the waveforms of Figure 7(c).
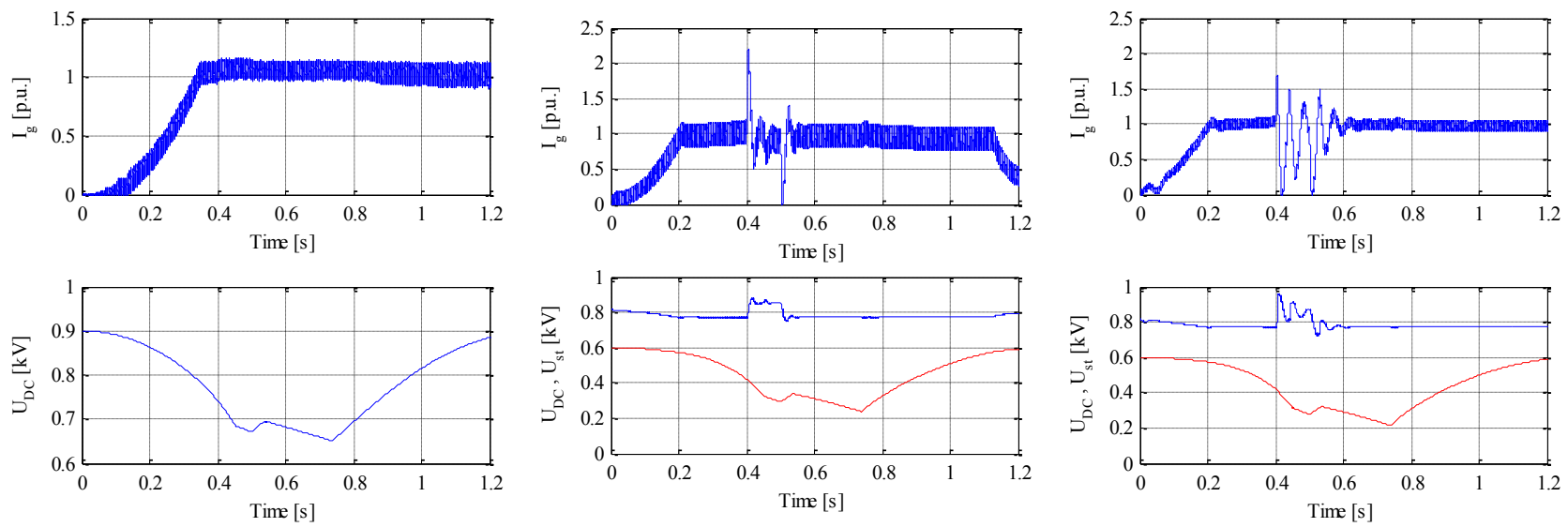

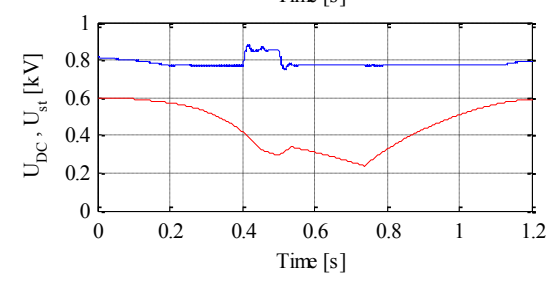

(b)

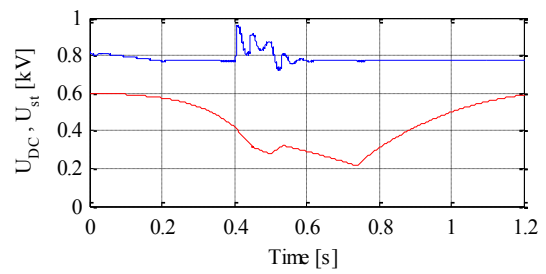

(c) 
Figure 7: Simulation results of grid current (top) and storage element voltage (bottom) of the (a) boost converter (b) two quadrant converter with power balance control stategy and (c) two quadrant converter with a rule-based control strategy.

\section{Grid disconnect transients}

The graphs in Figure 8 demonstrate the behaviour of the three circuit variants during a temporary (50ms) grid disconnection event. The continuity of operation in the case of series connected Boost converter is ensured by the DC-link capacitor holdup time. Since at peak magnet power the DC-link capacitor provides in any case $80-90 \%$ of the power the temporary disconnection of the grid does not significantly influence its voltage as can be seen in Figure 8(a).
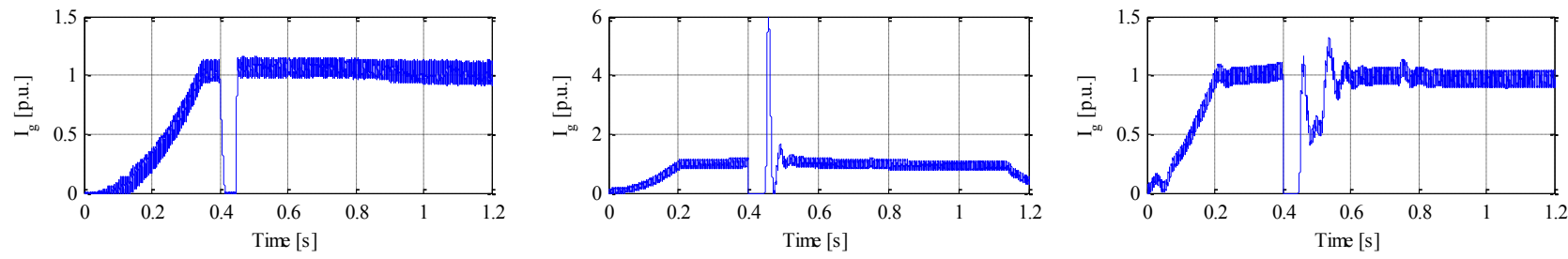

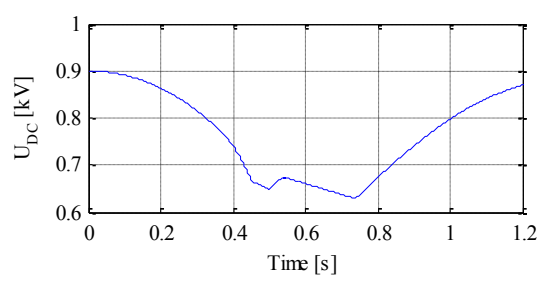

(a)

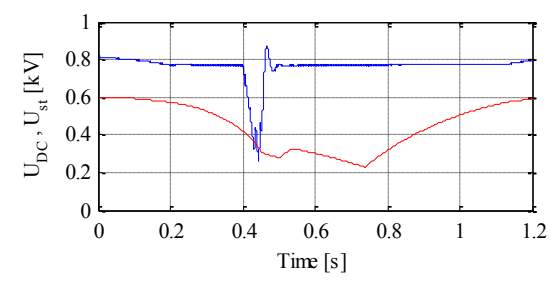

(b)

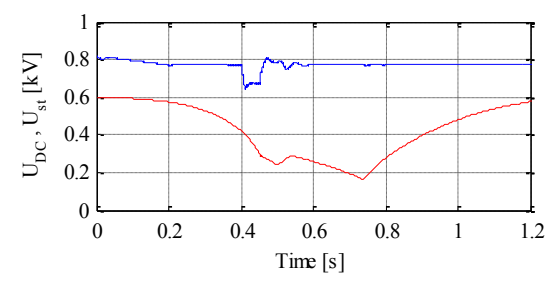

(c)

Figure 8: Grid current waveforms (top) and energy storing capacitor voltage (bottom) simulated during a 50ms grid disconnection event. (a) Boost converter (b) two-quadrant converter with power balance control strategy and (c) twoquadrant converter with rule-based control strategy

Since the 2Q converter with a Power Balance Control strategy doesn't include a direct DC-link voltage regulation, this voltage will decrease, either to a value lower than the required minimum (thus interrupting the operation of the magnet power supply) or below the storage element voltage (hence losing control of the current in the 2Q converter). The overcurrent caused when the grid reconnects is significant (6 p.u.).

The 2Q converter with Rule Based Control strategy features a DC-link voltage regulation which acts as soon as the voltage gets below the set "recovery" threshold $(650 \mathrm{~V})$. The voltage is, hence, stabilized to this value. When the grid voltage becomes normal the overcurrent is limited by the overcurrent protection system (as explained in the section IV).

\section{DISCUSSION OF RESULTS}

The choice of a topology for a magnet power supply is based on technical and economic criteria that have been described in previous paragraphs. A number of metrics are being defined to allow the designer evaluate the effectiveness of a proposed solution. The metrics are presented in TABLE 5 and concern the input power quality, the utilisation factor of the energy storing elements and the semiconductor peak current ratings.

TABLE 5: LIST OF FIGURES OF MERIT

\begin{tabular}{clll}
\hline Parameter & Description & Boost & $\mathbf{2 Q}$ \\
\hline$I_{\text {g,peak }} / I_{\text {g,rating }}$ & Grid overload factor & $111 \%$ & $125 \%$ \\
$E_{\text {st,max }} / E_{\text {magnet }}$ & Installed energy capacity & $314 \%$ & $145 \%$ \\
$\Delta E_{\text {st }} / E_{\text {st,max }}$ & Capacitor utilisation factor & $52 \%$ & $85 \%$ \\
$I_{\text {converter,peak }} / I_{\text {m,peak }}$ & Peak current in additional converter & $26 \%$ & $113 \%$ \\
$I_{\text {converter,RMS }} / I_{m, R M S}$ & RMS current in additional converter & $34 \%$ & $56 \%$ \\
\hline
\end{tabular}

The $I_{\text {g,peak }} / I_{\text {g,rating }}$ parameter is indicative of the peak grid current values the system draws with respect to its rated RMS current. A lower value, indicate a system capability to limit the current (and, consequently, the power) taken from the grid in all grid conditions. This parameter is always greater than 1, given the ripple component (Boost) and/or the $300 \mathrm{~Hz}$ current undulation (Boost/2Q).

The installed energy capacity $\left(E_{s t, \text { max }} / E_{\text {magnet }}\right)$ is a quantifier of how much energy storage has to be installed, relative to the magnet energy rating. Its value is as following: 


$$
\frac{E_{s t, \text { max }}}{E_{\text {magnet }}}=\frac{\frac{1}{2} \cdot C_{s t} \cdot U_{s t, \text { rated } \max }^{2}}{\frac{1}{2} \cdot L_{\text {magnet }}\left(I_{\text {magnet }, \text { max }}\right) \cdot I_{\text {magnet,max }}^{2}}
$$

This value is representative of the volume taken by the energy storage unit. It is also an indication of the cost as well as mass of this energy storage system. The lower this value, the more the energy storage unit will be space-efficient. This value is always greater than 1. During ramp-up for "small" magnets this installed energy may actually be smaller if the grid is able to deliver all required energy. However, during ramp down, the full magnet energy will need to be able to be recovered into the storage capacitors, therefore the storage system capacity (in $\mathrm{kJ}$ ) will need be higher than the magnetic load energy storing capability.

The $\Delta E_{s t} / E_{s t \text { max }}$ parameter is representative of how well the energy storage system is utilised. This value is between 0 and 1 . The higher this value, the more the storage element is exploited. The lower this value, the more the storage element is oversized with respect to the magnet maximum stored energy.

The $I_{\text {converter,peak }} / I_{\text {m,peak }}$ parameter is representative of which will be the magnetics saturation profile and, consequently, their size/cost. It also shows how the storage element IGBTs will need to be oversized with regards to the IGBTs of the magnet power supply unit. A value near (or lower than) 1 indicates that the similar current ratings can be assumed for semiconductors and magnetic components of the magnet supply (i.e. full bridge) and the grid supply units (e.g. boost converter). A value much bigger than 1 means that the power stack will need to be oversized and the magnetics will require a broader current saturation profile than the output chokes of the magnet supply unit, thus increasing their size and cost. Similarly the figure $I_{\text {converter,RMS }} / I_{m, R M S}$ indicates the thermal ratings ratio of the semiconductor and magnetics of the magnet supply and the energy storing converter. Furthermore this is an indication of the thermal stress on the energy storing capacitors.

As can be seen in TABLE 5 the 2Q uses better the installed energy capacity. However, as has been seen this comes with the disadvantage of poorer controllability over the grid current (especially during grid transients) and with the cost of higher current in the 2-quadrant converter components (semiconductors, DC chokes). It can be concluded that fewer energy storing capacitors will have the adverse effect of higher peak power flows being processed by the 2-quadrant converter. Effectively, to limit the grid power flow the output power of the magnet power supply needs to be almost entirely supplied by a $2 \mathrm{Q}$ converter. The latter has a detrimental effect on the semiconductors peak current rating. This is due to the highly varying voltage of energy storing capacitors that, on one hand, improves the capacitor utilisation factor and, on the other hand, increases the semiconductor peak current to be supplied during the low capacitor voltage instances.

\section{CONCLUSIONS}

This study has presented two topological variations to the standard magnet power supply in order to manage the recovered energy stored in large electro-magnets in Physics applications. The proposed topologies along with cycling current operation allow to reduce the requirements in terms of RMS power from the grid. Both DC-DC regulators, the series connected boost and the parallel connected 2-quadrant converter, allow operation during grid perturbations and in case of a 50ms grid disconnection. The analysis presented in this work indicates that a boost regulator results in lower amplitude transients after recovery from a severe grid event. The 2-quadrant converter being connected in parallel to the DC-link capacitors naturally lags in response to grid disturbances unless the grid current is directly measured with a current sensor. A Rule Based Control enables the 2-quadrant converter to respond to grid overvoltages by enabling a high gain loop that increases the main DC-link voltage hence blocking the diode rectifier current. The power stage of a 2-quadrant converter will have to process virtually all of the magnet peak power as the grid power flow needs to be limited. This result in an additional power stage of almost equal power ratings (and higher peak currents) as the magnet power supply. The boost converter on the other hand handles only the grid power flow which in the case of a magnet power supply can be a fraction of the peak power.

\section{REFERENCES}

[1] S.Maestri, R.G.Retegui, G.Uicich, M.Benedetti, G.L.Godec, K.Papastergiou, Control strategies for 2-quadrant converter used in grid power flow control, European Power Electronics Conference (EPE), Geneve, 2015 to appear.

[2] S. Tadakuma and M. Ehara, "Historical and predicted trends of industrial AC drives", in Proc. of the International Conference on Industrial Electronics, Control, and Instrumentation, (IECON), vol.2, pp. 655-661, 15-19 Nov. 1993.

[3] P. Chopade, M. Bikdash, I. Kateeb, A.D. Kelkar, "Reactive power management and voltage control of large Transmission System using SVC (Static VAR Compensator)", in Proc. of IEEE South East Conference (SouthEastCon), pp.85-90, 17-20 March 2011.

[4] M.J. Katira, K.B. Porate, "Load flow analysis of $132 / 11 \mathrm{kV}$ distribution sub station using static var compensator for voltage enhancement - A case study", IEEE Region 10 Conference (TENCON), pp.1-5, 23-26 Jan. 2009.

[5] J.-H. Chen, W.-J. Lee, M.-S. Chen, "Using a static VAr compensator to balance a distribution system", IEEE Transactions on Industry Applications, vol.35, no.2, pp. 298-304, Mar/Apr 1999. 
[6] ABB, "SVC - Static Var Compensator - An insurance for improved grid system stability and reliability", March 2015, [Online]. Available: https://library.e.abb.com/.

[7] ABB, "SVC - Static Var Compensator - The key to better arc furnace economy", June 2010, [Online]. Available: https://library.e.abb.com/.

[8] ABB, "Reactive power compensation - Installation of new reactive power compensation equipment on RTE's grid in France", Oct 2009, [Online]. Available: https://library.e.abb.com/.

[9] L. Huber, J. Yungtaek, M.M. Jovanovic, "Performance Evaluation of Bridgeless PFC Boost Rectifiers", IEEE Transactions on Power Electronics, vol.23, no.3, pp.1381-1390, May 2008.

[10] J.P.M. Figueiredo, F.L. Tofoli, B.L.A. Silva, "A review of single-phase PFC topologies based on the boost converter", 9th IEEE/IAS International Conference on Industry Applications (INDUSCON), pp.1-6, 8-10 Nov. 2010

[11] Exhibition on Ecological Vehicles and Renewable Energies (EVER), pp.1-6, 27-30 March 2013 